\title{
Mechanical Properties and Durability of Fiber-reinforced Concrete
}

\author{
Jingjing Zhang ${ }^{1, *}$, Jianwei Cheng ${ }^{2}$, Yuanming Dou ${ }^{1}$ and Qin Xin ${ }^{1,3}$ \\ ${ }^{1}$ School of Civil and Transportation Engineering, Hebei University of Technology, Tianjin 300401, China \\ ${ }^{2}$ China Fortune Land Development, Langfang 065011, China \\ ${ }^{3}$ Department of Electrical Engineering, Wayne State University, Detroit, MI 48202, United States
}

Received 29 March 2017; Accepted 1 October 2017

\begin{abstract}
Traditional methods of pasting carbon and aramid fiber sheets or boards on concrete are usually adopted for concrete reinforcement due to the high brittleness and poor toughness of concrete. However, many factors affect the use of these methods, and the characteristics of fiber materials are not maximized. This study proposed a test model in which chopped carbon, aramid, and hybrid carbon-aramid fibers $(1: 1)$ were directly added to concrete to fully utilize the high strength and toughness of fibers and improve the properties of concrete. The influence of different types and mixing ratios of fibers on the mechanical properties and durability of concrete was analyzed through axial compressive strength, static elastic modulus, and carbonation tests. A calculation model based on the axial compressive strength, carbon dioxide concentration, and carbonization time of concrete was developed with existing carbonation depth calculation models and verified using experimental data. Results demonstrate that the compressive strength, elastic modulus, and anticarbonization capacity of the fiber-reinforced concrete initially increase and then decrease with an increase in fiber content and are better than those of ordinary concrete. The compressive strength and elastic modulus of the hybrid fiberreinforced concrete with a mixing ratio of $1 \%$ increase the most among all of the studied concrete samples, and the anticarbonation capacity of the carbon fiber-reinforced concrete with a mixing ratio of $1 \%$ is the best. The proposed method provides a reference for practical property and durability evaluation of fiber-reinforced concrete in practical engineering.
\end{abstract}

Keywords: Carbon Fiber, Aramid Fiber, Compressive Strength, Elastic Modulus, Carbonization

\section{Introduction}

The large weight, brittleness, and poor durability of concrete have been well investigated due to the extensive application of concrete as a building material in the building industry. Researchers have applied fiber boards or sheets for structure reinforcement and repair to improve the inherent inferior properties of concrete by maximizing the light weight and high fracture toughness of fibers. Performance has been verified to be excellent. However, traditional fiber sheets or boards exert a good reinforcement effect in the parallel direction of the fiber but exhibit poor performance in the vertical direction. The stress state of components subjected to stresses in multiple directions simultaneously is often unpredictable. Continuous fiber exerts a limited reinforcement effect in this case, and its utilization ratio is reduced. Accurately determining the reinforcement degree is also difficult. The stiffness of components can increase significantly after reinforcement, and such an increase could result in the stripping of the reinforcement material and cause sudden rupture of the components. The reinforcement effect also depends on the performance of the adhesive material. Construction requires manpower, material resources, and money, which are neither economic nor environment friendly. Thus, the bearing capacity and durability of concrete should be improved by changing the

*E-mail address: 15022741875@163.com

ISSN: 1791-2377 @ 2017 Eastern Macedonia and Thrace Institute of Technology. All rights reserved. doi:10.25103/jestr.105.08 properties of concrete.

Domestic and foreign scholars have presented a method of directly mixing chopped fibers with concrete to maximize the advantages of fiber materials, reduce the weight of the structure, and improve the mechanical properties of concrete. Fibers are distributed randomly in large numbers within a sample to share stresses originating from different directions and thus improve component performance, avoid brittle fracture, and increase the utilization ratio of fibers[1].

Carbon fiber in fiber-reinforced concrete has been extensively studied because of its high strength, high modulus, small specific gravity, and high toughness[2-3]. Aramid fiber, a new type of fiber for concrete reinforcement, has elicited much attention from domestic and foreign scholars due to its high strength, high modulus, light weight, and high resistance to corrosion and fatigue[4-5]. Recent studies on aramid fiber-reinforced concrete have focused on pasting aramid fiber sheets on the surfaces of building components to improve the bearing capacity of structures[67]. However, only a few studies have examined the direct application of aramid fiber in concrete in the form of chopped fiber. Therefore, chopped carbon, aramid, and hybrid carbon-aramid fibers were directly added to concrete in this study to analyze the basic mechanical properties and durability of the added materials.

\section{State of the art}

Researchers have conducted numerous studies on fiber sheet or board reinforcement. Dong et al.[8] tested the bending 
performance of five reinforced concrete beams with rectangular sections and found that externally pasting carbon fiber sheets effectively increase the limit-bearing capacity and deformation resistance of beams, delay the development of concrete cracks, and significantly improve the overall rigidness of reinforced beams. However, when the researchers reinforced pre-cracked beams through the same method, the bending capacity and ductility of the beams were reduced. Cheng et al.[9] also pasted carbon fiber sheets on continuous concrete beams for reinforcement. The method did not increase the bearing capacity of components in the elastic state but significantly increased it in the plastic state. The reinforced continuous beams showed that internal force was redistributed. Shang et al.[10] found that the interfacial bond between a carbon fiber board and concrete is a key reinforcement property and exerts an important effect on the mechanical behavior and failure modes of reinforced structures. Wen [11] measured the damage resistance of a carbon fiber composite material and calculated the degree of damage on the basis of the changes in resistance. Deng et al.[12] performed a bending test on 11 reinforced concrete beams and found that when stress transfer is unstable, the hybrid fiber cloth is partially removed from the concrete, and a poor reinforcement effect is obtained. According to these studies, reinforcement is not guaranteed when fiber sheets or boards are used to reinforce components. Instead, the bearing capacity of components increases and their ductility decreases; this scenario can even cause the stripping damage of reinforcement materials. As a result, fiber performance is not maximized.

The method of mixing fiber with concrete has been proposed to avoid ductility reduction and maximize the advantages of fiber materials. Song and Yin[13] conducted compression and impact resistance tests on hybrid fiberreinforced concrete. They found that although the compressive strengths of steel and carbon fiber-reinforced concrete (CFRC) are improved, the improvement in the strength of the hybrid fiber-reinforced concrete is more significant. Impact resistance improves with an increase in fiber volume. The researchers also studied the positive effect of steel and carbon fiber-reinforced concrete on the basis of the experimental results. He et al.[14] investigated the dynamic characteristics of hybrid carbon-aramid fiberreinforced concrete (C/AFRC) and discovered that flexible fiber-reinforced concrete can bear serious deformation; this method of concrete reinforcement increases the energy dissipation of materials, improves dynamic performance, and exerts an evident damping effect. Zhang et al.[15] found that incorporating aramid fiber into cement mortar improves the flexural strength and shock resistance of the material. Performance is maximized when the volume fraction of doped fiber is 1.0\%. Qiao et al.[16] discovered that aramid fiber-reinforced concrete (AFRC) possesses better crack resistance than polypropylene fiber-reinforced concrete. Moreover, aramid demonstrates good strength and toughening performance at low water/cement ratios and in standard curing conditions. These studies focused on the effect of aramid fiber on enhancing the dynamic performance, impact resistance, and crack resistance of concrete, and limited research has been conducted on the influence of aramid fiber on enhancing the basic mechanical properties of concrete and the effect of hybrid carbon aramid fibers on carbonation performance.

To address the deficiencies of existing studies, we mixed carbon, aramid, and hybrid carbon - aramid fibers with concrete and performed axial compressive, static elastic modulus, and carbonation tests to analyze the mechanical properties and durability of fiber-reinforced concrete. This work provides a reference for the application of fiberreinforced concrete in engineering.

The remainder of this study is organized as follows. Section 3 introduces the test scheme and test system. Section 4 provides an analysis of the basic mechanical properties of fiber-reinforced concrete on the basis of experimental data and presents a carbonation depth calculation model established according to influencing factors. Section 5 summarizes the conclusions.

\section{Methodology}

\subsection{Test Introduction}

Sixty prism samples with dimensions of $150 \mathrm{~mm} \times 150 \mathrm{~mm}$ $\times 300 \mathrm{~mm}$ and a concrete grade of C40 were designed for axial compressive and static elastic modulus tests. Thirty prism samples with dimensions of $100 \mathrm{~mm} \times 100 \mathrm{~mm} \times$ $300 \mathrm{~mm}$ and with the same concrete grade were designed for the carbonation test. Two factors, namely, fiber type and fiber mixing rate (containing three levels each), were used. The samples were divided into 10 groups according to the principle of orthogonal experiments, as shown in Table 1.

Table 1. Orthogonal test scheme

\begin{tabular}{c|c|c|c}
\hline Test group & Fiber type & Fiber doping rate & Number \\
\hline 1 & -- & -- & 3 \\
(Control group) & & & \\
2 & $\mathrm{C}$ & $0.5 \%$ & 3 \\
3 & $\mathrm{C}$ & $1 \%$ & 3 \\
4 & $\mathrm{C}$ & $1.5 \%$ & 3 \\
5 & $\mathrm{~A}$ & $0.5 \%$ & 3 \\
6 & $\mathrm{~A}$ & $1 \%$ & 3 \\
7 & $\mathrm{~A}$ & $1.5 \%$ & 3 \\
8 & $\mathrm{C} / \mathrm{A}$ & $0.5 \%$ & 3 \\
9 & $\mathrm{C} / \mathrm{A}$ & $1 \%$ & 3 \\
10 & $\mathrm{C} / \mathrm{A}$ & $1.5 \%$ & 3 \\
\hline
\end{tabular}

Note: $\mathrm{C}$ stands for carbon fiber, A stands for aramid fiber, and C/A represents hybrid fiber.

\subsection{Sample Preparation}

Ordinary Portland cement with a strength grade of 42.5 was used. Ordinary sand was utilized as the fine aggregate, and gravel with a maximum diameter of $30 \mathrm{~mm}$ was adopted as the coarse aggregate. Tap water was also used. The mixing proportion of concrete was as follows: water: sand: gravel: water-reducing agent $=1: 0.39: 1.29: 2.88: 1 \%$. The concrete was artificially mixed. The post-fiber mixing method was applied in preparing concrete to disperse the fiber well and maximize its toughness. The samples were removed from the mold after being poured for $24 \mathrm{~h}$ and maintained for $28 \mathrm{~d}$ in a standard curing room with $90 \%$ humidity and $20^{\circ} \mathrm{C}$ temperature to allow the samples' strength to reach the maximum value. The specific parameters of the fiber in this test are shown in Table 2 .

\subsection{Test Equipment and Method}

The axial compressive test was conducted on a $5000 \mathrm{kN}$ pressure testing machine, which is shown in Fig. 1. The loading process was controlled by stress. The samples were placed on the platform of the testing machine, and load was applied on the samples along the axial direction at a rate of $0.5 \mathrm{MPa} / \mathrm{s}$ until the samples failed. The specific axial compressive strength was then obtained. The test data were automatically collected by the test system. 
Table 2. Fiber parameters

\begin{tabular}{c|c|c|c|c|c|c}
\hline Fiber type & $\begin{array}{c}\text { Density } \\
\left(\mathrm{kg} / \mathrm{m}^{3}\right)\end{array}$ & $\begin{array}{c}\text { Tensile strength } \\
(\mathbf{M P a})\end{array}$ & $\begin{array}{c}\text { Tensile modulus } \\
(\mathbf{G P a})\end{array}$ & $\begin{array}{c}\text { Elongation } \\
\mathbf{( \% )}\end{array}$ & $\begin{array}{c}\text { Fiber } \\
\text { diameter } \\
(\boldsymbol{\mu m})\end{array}$ & $\begin{array}{c}\text { Length } \\
(\mathbf{m m})\end{array}$ \\
\hline Carbon & 1750 & 3530 & 240 & 1.5 & 7 & 12 \\
Aramid & 1440 & 3150 & 80 & 3.6 & 2 & 2 \\
\hline
\end{tabular}

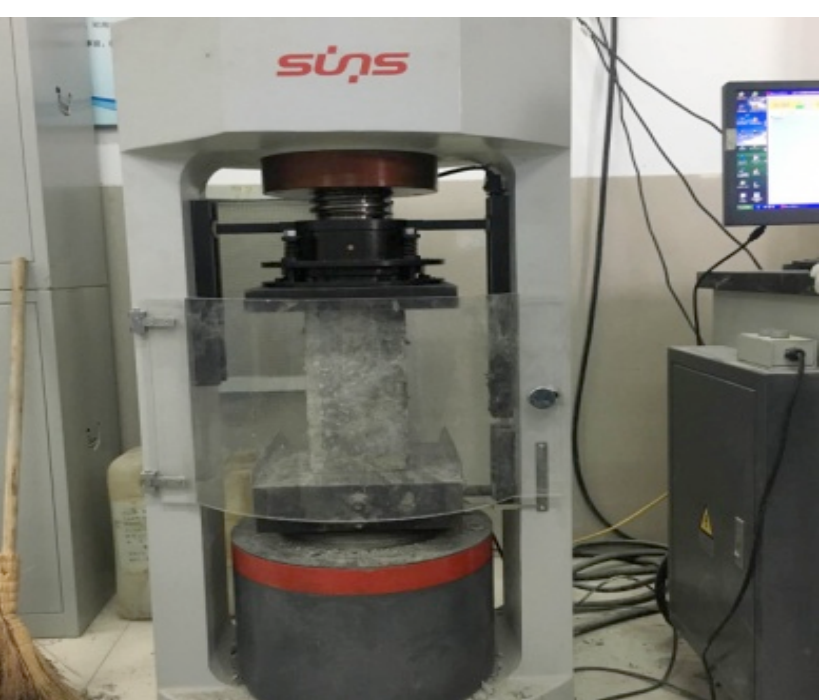

Fig. 1. Pressure testing machine at $5000 \mathrm{kN}$

The static elastic modulus test was conducted on a 2000 $k N$ pressure testing machine built by Shanghai Science Zongheng Machine Manufacturing Co., Ltd. The amount of deformation was measured by a strain gauge with a pasting range of 15,000 on both sides of the prism and at a standard distance of $150 \mathrm{~mm}$. Data were collected with a WKD3811A multifunctional static strain gauge produced by Tianjin Weekend (Fig. 2).

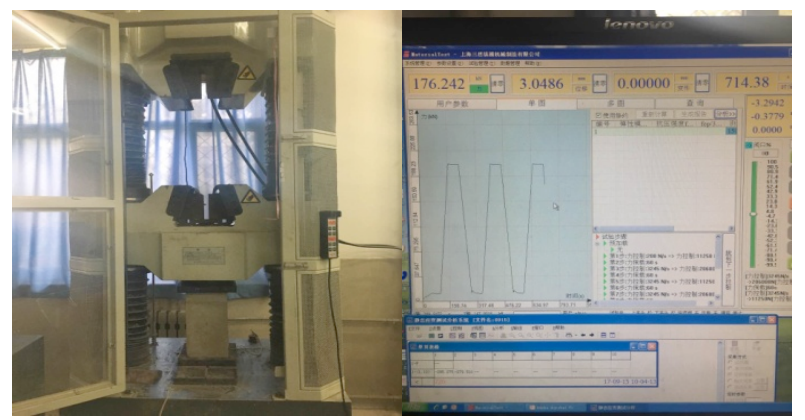

Fig. 2. Pressure testing machine at $2000 \mathrm{kN}$ and the data collection system

Load was applied to the initial load value at a benchmark stress of $0.5 \mathrm{MPa}$, which was $11,250 \mathrm{~N}$ in the test. The constant load was maintained for $60 \mathrm{~s}$, and the deformation reading of each measuring point within $30 s$ was recorded. The load was continuously and uniformly applied to the other loads immediately, with the stress being one-third of the axial compressive strength. The constant load was maintained for $60 \mathrm{~s}$, and the deformation reading of each measuring point within $30 \mathrm{~s}$ was recorded. Thereafter, the load on was unloaded. This loading process was repeated four times, and the strain values were recorded. Then, the load was applied at the same speed until the samples failed. The failure loads were recorded. The difference with the measured axial compressive strength should be less than $20 \%$. The static modulus of elasticity was calculated with the following equation.

$$
E_{\mathrm{c}}=\frac{F_{a}-F_{0}}{A} \times \frac{L}{\Delta n}
$$

where $E_{\mathrm{c}}$ is the elastic modulus of concrete $(\mathrm{MPa}) ; F_{a}$ is the load when the stress is one-third of the axial compressive strength $(\mathrm{N}) ; F_{0}$ is the initial load when the stress is $0.5 \mathrm{MPa}$; $A$ is the pressure area of the specimen $\left(\mathrm{mm}^{2}\right) ; L$ is the standard measuring distance $(\mathrm{mm})$; and $\Delta n$ is the average value of the deformations on both sides of the sample when $F_{0}$ is loaded to $F_{a}$ for the last time $(\mathrm{mm})$.

Prior to the carbonation test, the samples that had been cured for $28 \mathrm{~d}$ were placed in a drying box for continuous drying at $60{ }^{\circ} \mathrm{C}$ for $48 \mathrm{~h}$. The surfaces of the dried samples were evenly coated with heated wax for sealing, except for the two opposite sides. Parallel lines were drawn with a pencil on the reserved sides at an interval of $10 \mathrm{~mm}$ along the length direction to predetermine the measuring points of carbonation depth. Then, the samples were placed in an NJW-TH-9 computer automatic concrete carbonation test chamber manufactured by Beijing Naiheng Technology Development Co., Ltd., for carbonation at a humidity of $70 \pm 5 \%$, temperature of $20 \pm 5^{\circ} \mathrm{C}$, and $\mathrm{CO}_{2}$ concentration of $20 \pm 3 \%$, as shown in Fig. 3. The samples were subsequently removed from the carbonation text chamber on the 3rd, 7th, 14th, and 28th day and split by the pressure testing machine. The powder on the surface was cleaned, and $1 \%$ phenolphthalein alcohol solution was dropped on the surface. After $30 \mathrm{~s}$, the carbonation depths of the sections were measured at predetermined measuring points. The mean value of the data was used as the carbonation depth of the concrete sample.

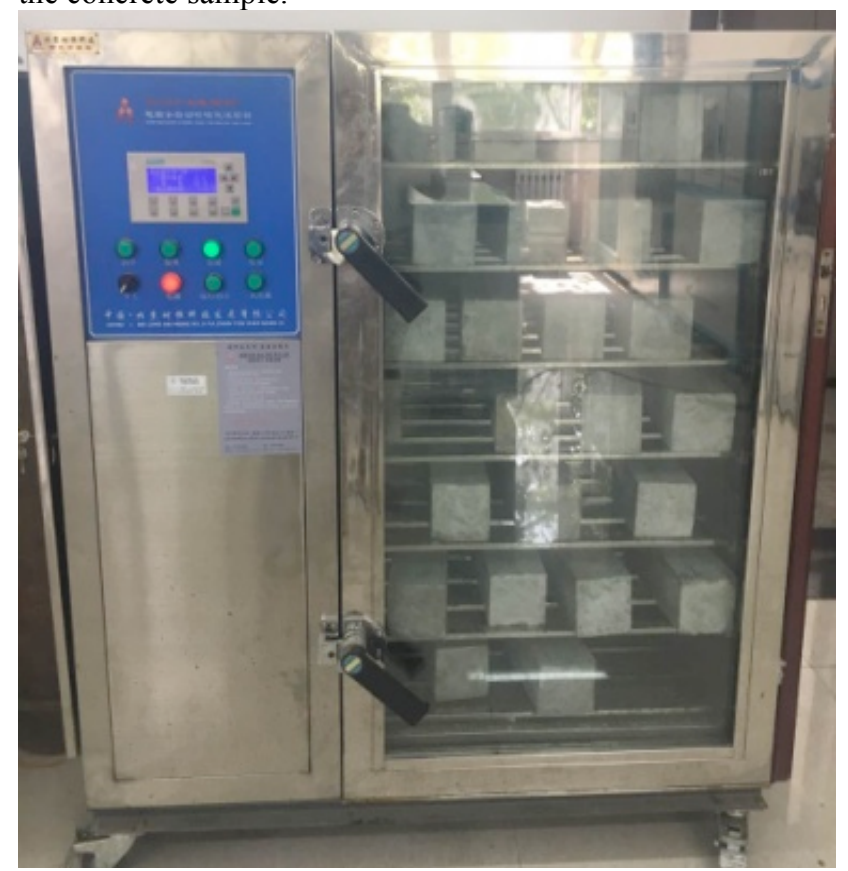

Fig. 3. Carbonation test chamber 


\section{Result Analysis and Discussion}

\subsection{Axial Compressive Test}

The axial compressive strength of concrete is an index that represents the mechanical properties of concrete and an important factor in the calculation of bearing capacity.
Standard values of the axial compressive strength of prisms were determined according to the designed test in Section 3.3 to analyze the specific effects of carbon, aramid, and carbon-aramid hybrid fibers on the mechanical properties of concrete and determine the optimal dosage and best performance. The results are shown in Table 3.

Table 3. Axial compressive strength

\begin{tabular}{|c|c|c|c|c|c|c|c|c|c|c|}
\hline \multirow{3}{*}{ Number } & \multicolumn{10}{|c|}{ Fiber content } \\
\hline & \multirow{2}{*}{$\mathbf{0}$} & \multicolumn{3}{|c|}{$0.5 \%$} & \multicolumn{3}{|c|}{$1 \%$} & \multicolumn{3}{|c|}{$1.5 \%$} \\
\hline & & $\mathbf{C}$ & A & C/A & $\mathbf{C}$ & $\mathbf{A}$ & $\mathbf{C} / \mathbf{A}$ & $\mathrm{C}$ & A & $\mathbf{C} / \mathbf{A}$ \\
\hline 1 & 27.5 & 28.4 & 41.9 & 28.6 & 29.5 & 26.3 & 32.2 & 28.2 & 24.2 & 24.8 \\
\hline 2 & 36.3 & 27.7 & 28.7 & 27.0 & 30.3 & 27.4 & 29.6 & 29.9 & 23.3 & 28.3 \\
\hline 3 & 27.3 & 28.1 & 29.1 & 27.5 & 28.8 & 26.5 & 30.9 & 28.7 & 23.7 & 28.7 \\
\hline Average & 27.5 & 28.1 & 29.1 & 27.7 & 29.5 & 26.7 & 30.9 & 28.9 & 23.7 & 27.3 \\
\hline Improvement $(\%)$ & - & 2.18 & 5.82 & 0.73 & 7.27 & -2.91 & 12.36 & 5.09 & -13.82 & -0.73 \\
\hline
\end{tabular}

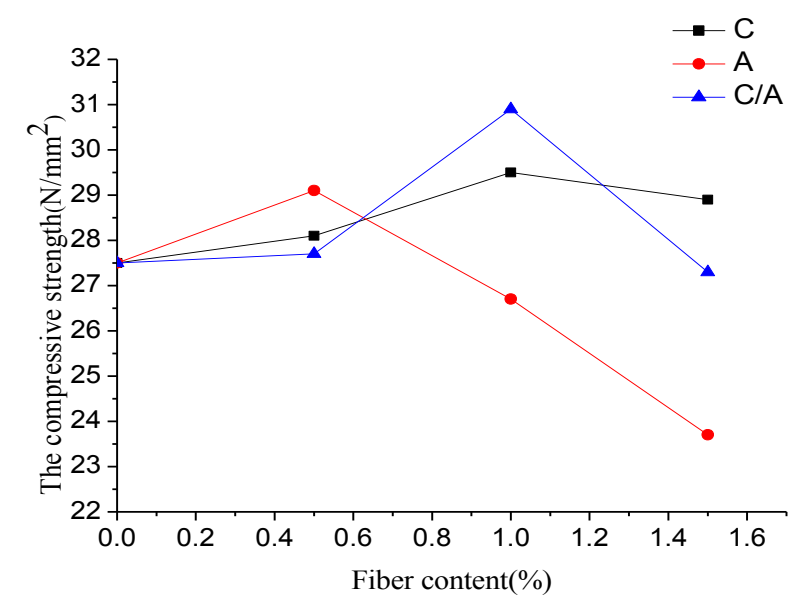

Fig. 4. Compressive strength with different fiber contents

Fig. 4 shows that with the increase in fiber content, the compressive strength of concrete initially increased and then decreased. The compressive strength of the hybrid fiberreinforced concrete sample with a mixing ratio of $1 \%$ increased the most (approximately 12\% increment). When the fiber content was small, the fibers were uniformly dispersed to maximize the advantage of high tensile strength. Energy was dissipated in the loading process due to the pullout and fracture of fibers, and this condition increased the overall compressive strength of the sample. When the mixing ratio of fibers was $1.5 \%$, the fibers were too plenty to be dispersed. They easily agglomerated in the mixing process, which made the concrete weak and led to a slight decline in compressive strength. Different fibers exerted different influences on the compressive strength of concrete. Carbon fiber performed better than aramid fiber in increasing compressive strength because the density of aramid fiber was lower than that of carbon fiber. At the same volume-fraction fiber content, the amount of aramid fiber increased, which affected the compactness of concrete and reduced the compressive strength of concrete. However, when aramid and carbon fibers were mixed into the concrete samples, the synergy maximized the advantages of these fibers and thus greatly improved the compressive strength of concrete.

A significant difference in the failure process of the fiber-reinforced and ordinary concrete was observed during the test. X-shape cracks occurred in the section of the ordinary concrete prism sample under loading. When the ultimate load was reached, the concrete broke down, and its strength suddenly decreased, indicating typical brittle failure During the loading process of the fiber-reinforced concrete samples, compressive toughness increased significantly due to fiber crack resistance and toughening. When $40 \%$ of the ultimate load was applied, vertical micro cracks occurred in the middle of the samples. The cracks extended to both ends as the load increased, and new vertical cracks occurred. The cracks developed obliquely at the ends with new bifurcated cracks. The pull-out and fracture sounds of the fiber inside the samples were heard. Upward and downward cracks developed when the ultimate load was applied. The bearing capacity began to decline, which indicated sample failure. Concrete spalling, which is a characteristic of ductile fracture, was not observed in the entire process.

\subsection{Static Elastic Modulus Test}

\subsubsection{Test Results}

Carbon and aramid fibers possess high modulus, but estimating their effects on improving the elastic modulus of concrete after mixing is impossible. Thus, a static elastic modulus test was conducted to obtain the parameter values. The corresponding elastic modulus of the fiber-reinforced concrete was calculated with Formula (1) and is shown in Table 4.

Table 4. Elastic modulus $\left(\times 10^{4}\right)$

\begin{tabular}{|c|c|c|c|c|c|c|c|c|c|c|}
\hline \multirow{3}{*}{ Number } & \multicolumn{10}{|c|}{ Fiber content } \\
\hline & \multirow{2}{*}{$\mathbf{0}$} & \multicolumn{3}{|c|}{$0.5 \%$} & \multicolumn{3}{|c|}{$1 \%$} & \multicolumn{3}{|c|}{$1.5 \%$} \\
\hline & & $\mathbf{C}$ & $\mathbf{A}$ & C/A & $\mathbf{C}$ & $\mathbf{A}$ & C/A & $\mathbf{C}$ & $\mathbf{A}$ & $\mathbf{C} / \mathbf{A}$ \\
\hline 1 & 3.31 & 3.28 & 3.39 & 3.27 & 3.44 & 3.19 & 3.56 & 3.41 & 3.26 & 3.39 \\
\hline 2 & 3.27 & 3.33 & 3.37 & 3.35 & 3.51 & 3.32 & 3.59 & 3.45 & 3.20 & 3.32 \\
\hline 3 & 3.29 & 3.35 & 3.34 & 3.31 & 3.49 & 3.27 & 3.67 & 3.38 & 3.17 & 3.20 \\
\hline Average & 3.29 & 3.32 & 3.37 & 3.31 & 3.48 & 3.26 & 3.61 & 3.41 & 3.21 & 3.30 \\
\hline Improvement $(\%)$ & -- & 0.91 & 2.43 & 0.61 & 5.78 & -0.91 & 9.73 & 3.65 & -2.43 & 0.30 \\
\hline
\end{tabular}



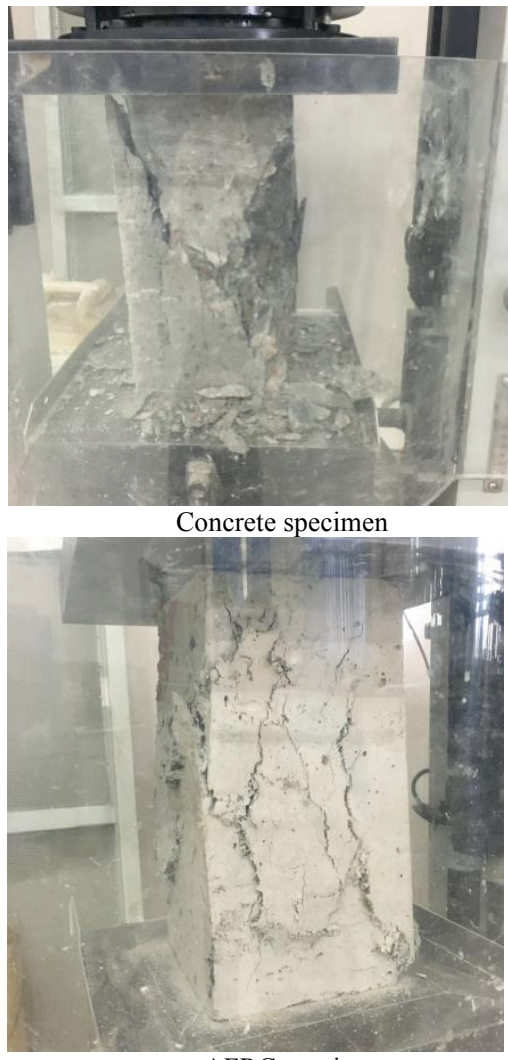

AFRC specimen

Fig. 5. Failure diagram of specimens

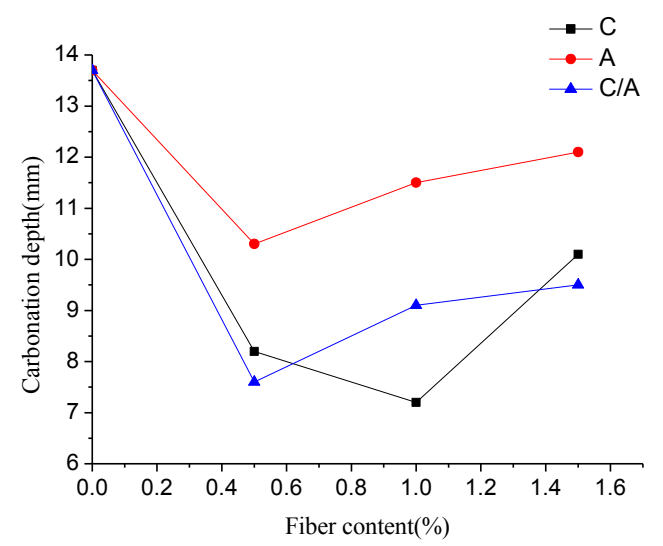

Fig. 6. Elastic modulus of concrete with different fiber contents

Analysis of the data in Table 4 indicated that the elastic modulus and compressive strength of concrete presented the same change trend. The elastic modulus of the fiberreinforced concrete increased with the increase in axial compressive strength. The elastic modulus of the $1 \%$ hybrid fiber-reinforced concrete increased the most (approximately $10 \%$ increment). Fig. 6 presents the change in the elastic modulus of concrete with different fiber contents. The elastic modulus of the concrete mixed with carbon and hybrid fibers was higher than that of ordinary concrete. The hybrid fiber exerted the best enhancement effect among all the studied fibers. When the aramid fiber content was high, the elastic modulus of aramid fiber was slightly smaller than that of ordinary concrete. The addition of fiber in concrete generally increased the elastic modulus, but the improvement was less
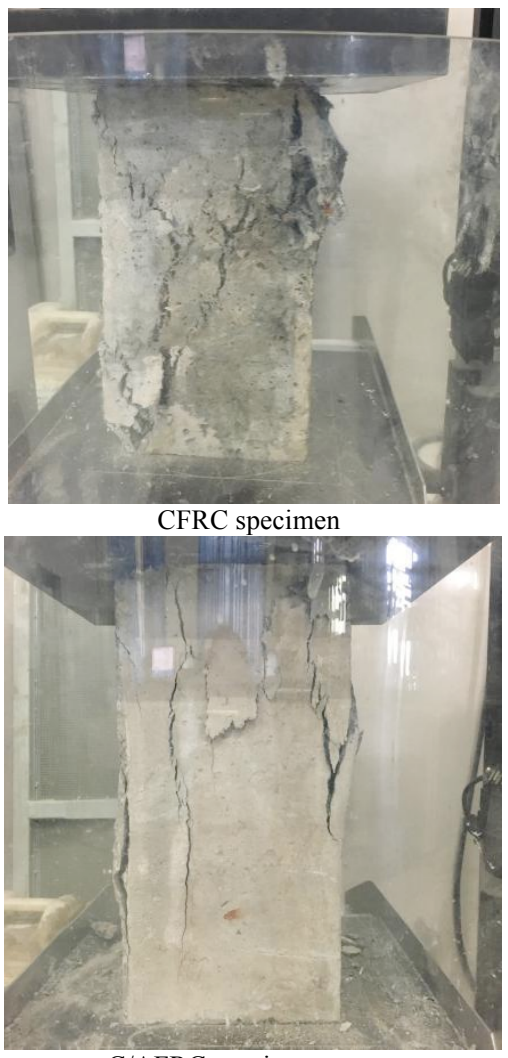

C/AFRC specimen

than $10 \%$. Thus, the elastic modulus of ordinary concrete was directly used in the calculation process.

\subsubsection{Selection of Elastic Modulus Calculation Methods}

Many empirical formulas can be utilized to calculate the elastic modulus of concrete. These formulas can be classified into three main types according to compressive strength.

The calculation formula proposed by the European Concrete Association (ECA) is as follows:

$$
E_{\mathrm{c}}=9.5\left(f_{c u}+8\right)^{1 / 3}
$$

where $E_{c}$ refers to elastic modulus $\left(\mathrm{N} / \mathrm{mm}^{2}\right)$ and $f_{c u}$ refers to compressive strength $\left(\mathrm{N} / \mathrm{mm}^{2}\right)$.

The calculation formula of concrete under C60 according to China's concrete structure design code (CCDC) is as follows:

$$
E_{\mathrm{c}}=\frac{10^{5}}{2.2+\frac{34.7}{f_{c u}}}
$$

The calculation formula provided by Chen Zhaoyuan et al. $(\mathrm{CZY})$ is as follows:

$$
E_{\mathrm{c}}=\left(0.261 \sqrt{f_{c u}}+1.787\right) \times 10^{4}
$$

The reliability of these formulas was verified using the measured data. The results are shown in Table 5. 
Table 5. Calculated values of elastic modulus by different formulas

\begin{tabular}{|c|c|c|c|c|c|c|c|c|c|c|}
\hline \multirow{3}{*}{ Formula } & \multicolumn{10}{|c|}{ Fiber content } \\
\hline & \multirow{2}{*}{$\mathbf{0}$} & \multicolumn{3}{|c|}{$0.5 \%$} & \multicolumn{3}{|c|}{$1 \%$} & \multicolumn{3}{|c|}{$1.5 \%$} \\
\hline & & $\mathrm{C}$ & A & C/A & $\mathbf{C}$ & $\mathbf{A}$ & $\mathbf{C} / \mathbf{A}$ & $\mathbf{C}$ & $\mathbf{A}$ & $\mathbf{C} / \mathbf{A}$ \\
\hline ECA & 3.47 & 3.51 & 3.53 & 3.48 & 3.54 & 3.45 & 3.59 & 3.52 & 3.33 & 3.47 \\
\hline $\mathrm{CCDC}$ & 3.28 & 3.30 & 3.33 & 2.29 & 3.34 & 3.25 & 3.38 & 3.32 & 3.14 & 3.27 \\
\hline $\mathrm{CZY}$ & 3.54 & 3.47 & 3.50 & 3.46 & 3.52 & 3.43 & 3.56 & 3.50 & 3.34 & 3.45 \\
\hline Experimental data & 3.29 & 3.32 & 3.37 & 3.31 & 3.48 & 3.26 & 3.61 & 3.41 & 3.21 & 3.30 \\
\hline
\end{tabular}

The figures calculated with Formulas (2) and (4) are close, but they are larger than the experimental value. The figure calculated with Formula (3) fits the experimental value well. Thus, Formula (3) should be used to calculate the elastic modulus of fiber-reinforced concrete.

\subsection{Carbonation Test}

During the maintenance of concrete structures, calcium hydroxide and a saturated solution are produced by the hydration of cement filled into the pores of concrete and react with steel rods to form a layer of dense and insoluble $\mathrm{Fe}_{2} \mathrm{O}_{3}, \mathrm{Fe}_{3} \mathrm{O}_{4}$, and $\mathrm{Fe}(\mathrm{OH})_{3}$ on the surface known as a passive film. In this state, steel rods with micro cracks cannot be corroded by air and water, but when the alkalinity of concrete decreases due to a change in the external environment, the steel rods change from a passive state to an active state and begin to be corroded under the co-existence of water and carbon dioxide or chloride ions in the air.

In actual components, steel corrosion is the main factor that degrades the durability of concrete structures. The $\mathrm{CO}_{2}$ content in the air increases with the development of industries and increase in automobile usage, leading to concrete carbonation. Concrete carbonation is causes steel de-passivation and corrosion, which affect the durability of reinforced concrete structures. Therefore, analyzing the increase in the anti-carbonation capacity of concrete is crucial.

Fibers can improve the carbonation resistance of concrete because fibers are evenly distributed in cement mortar after being added to concrete. They connect with one another to form a network that inhibits aggregate submersion, prevents the segregation of concrete mixture, and decreases the bleeding of concrete, thereby reducing the number of pore channels in the concrete. Fibers that are largely distributed in the mortar also reduce and even block pores. The addition of fibers also reduces or prevents the formation, growth, and expansion of cracks in concrete and hinders crack connectivity. In other words, in fiber-reinforced concrete, fibers weaken the diffusion path of $\mathrm{CO}_{2}$. As a result, the anti-carbonation capacity of fiber-reinforced concrete is higher than that of ordinary concrete. In this study, the influence of fibers on the anti-carbonation capacity of concrete was further analyzed through an experiment.

\subsubsection{Test Results}

The carbonization depths of different fiber-reinforced concrete sample were obtained through a carbonation test, the design of which has been explained in Section 2.3. Given that the number of samples was large, the average value of three samples in a group was obtained. The carbonation depths of different groups of samples on the 3rd, 7th, 14th, and 28th day are listed in Table 6. The carbonation depth of concrete increased with age and increased rapidly in the first $7 d$ to nearly half of the final carbonation depth.

Table 6. Average carbonation depth

\begin{tabular}{|c|c|c|c|c|c|c|c|c|c|c|}
\hline \multirow{3}{*}{ Carbonation time } & \multicolumn{10}{|c|}{ Fiber content } \\
\hline & \multirow{2}{*}{$\mathbf{0}$} & \multicolumn{3}{|c|}{$0.5 \%$} & \multicolumn{3}{|c|}{$1 \%$} & \multicolumn{3}{|c|}{$1.5 \%$} \\
\hline & & $\mathbf{C}$ & $\mathbf{A}$ & C/A & $\mathbf{C}$ & $\mathbf{A}$ & C/A & $\mathbf{C}$ & $\mathbf{A}$ & $\mathbf{C} / \mathbf{A}$ \\
\hline $3 \mathrm{~d}$ & 3.1 & 0.9 & 2.2 & 2.4 & 0.7 & 2.7 & 1.3 & 1.6 & 2.9 & 0.8 \\
\hline $7 \mathrm{~d}$ & 9.3 & 4.1 & 5.3 & 4.1 & 3.6 & 6.9 & 4.2 & 5.6 & 6.3 & 4.4 \\
\hline $14 d$ & 11.9 & 6.3 & 8.3 & 6.0 & 5.8 & 9.7 & 8.6 & 8.9 & 10.2 & 7.9 \\
\hline $28 \mathrm{~d}$ & 13.7 & 8.2 & 10.5 & 7.6 & 7.2 & 11.3 & 9.1 & 10.1 & 12.1 & 9.5 \\
\hline
\end{tabular}

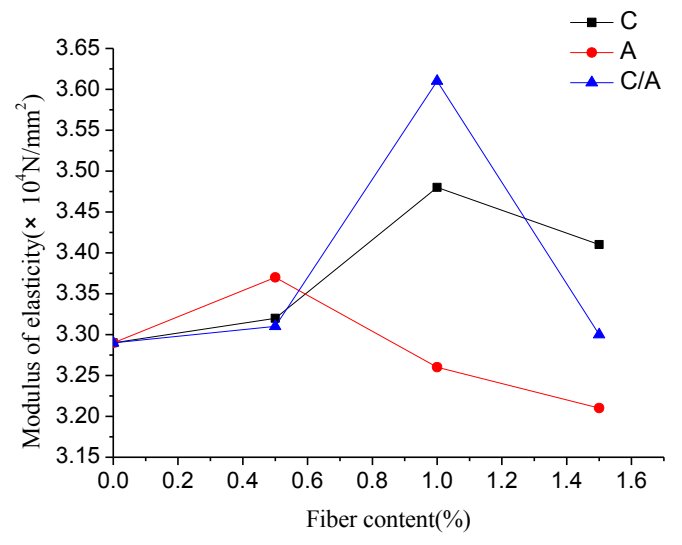

Fig. 7. Carbonation depths on the 28th day with different fiber contents
Fig. 7 shows that the carbonation depths of the concrete samples mixed with fiber were all smaller than those of ordinary concrete. Ordinary concrete exhibited poor anticarbonation performance because connected bleeding channels existed inside the concrete. These channels were the pore channels that remained after excess water evaporation and bleeding from the slurry. Water gaps accumulated at the edge of the coarse aggregate. The addition of fibers prevented the development of cracks. The fibers filled up the pores, thus enhancing the anticarbonation capacity of concrete.

The enhancement by anti-carbonation capacity was excellent when the fiber content was small. The effects of carbon and carbon - aramid hybrid fibers were better than that of the aramid fiber because a large amount of fiber led to uneven dispersion and agglomeration, thus resulting in poor compactness of concrete. 


\subsubsection{Carbonation Depth Calculation Model}

Given the importance of the carbonation resistance of concrete to the durability of components, local and international scholars have proposed various carbonation depth prediction models[17-18]. All studies have agreed that carbonation depth is proportional to the square root of carbonization time. The expression is as follows:

$$
x_{c}=k \sqrt{t}
$$

where $x_{c}$ refers to the carbonation depth $(\mathrm{mm}), k$ refers to the coefficient that influences carbonation, and $t$ refers to carbonization time.

To determine the value of $k$ and its influencing parameters, researchers have conducted many experimental studies on the $\mathrm{CO}_{2}$ diffusion coefficient, water-cement ratio, and compressive strength of concrete and have presented different calculation models. The representative models are as follows:

Theoretical model based on Fick's Law: A mathematical model based on the first law of diffusion and the absorption characteristics of $\mathrm{CO}_{2}$ in porous media was given by the former Soviet scholar Alexeyev[19] and his colleagues.

$x_{c}=\sqrt{\frac{2 D_{e, \mathrm{co}_{2}} C_{0}}{m_{0}}} \cdot \sqrt{t}$

where $D_{\mathrm{e}, \mathrm{co}_{2}}$ refers to the effective diffusion coefficient of $\mathrm{CO}_{2}$ in concrete, $\mathrm{C}_{0}$ refers to the carbon dioxide concentration on the surface of concrete, and $m_{0}$ refers to the volume of $\mathrm{CO}_{2}$ absorbed by concrete per unit volume when being fully carbonized.

Given that the mathematical-physical formula based on the $\mathrm{CO}_{2}$ diffusion coefficient is complex, the model is rarely applied.

Model based on diffusion theory and experiments: A mathematical model of carbonation depth was proposed by Zhang Yu et al.[20] from Tongji University.

$x_{c}=k_{R H} k_{C O_{2}} k_{T} k_{s} \times 839(1-R H)^{1.1} \sqrt{\frac{W / C \gamma_{c}-0.34}{\gamma_{H D} \gamma_{C}}} \sqrt{C_{C O_{2}}} \sqrt{t}$

where $W / C$ refers to the water-cement ratio; $C_{\mathrm{CO}_{2}}$ refers to the concentration of $\mathrm{CO}_{2} ; \mathrm{RH}$ refers to environmental humidity; $k$ refer to the parameters related to humidity, $\mathrm{CO}_{2}$ concentration, temperature, and stress state of concrete; $\gamma_{H D}$ refers to the correction coefficient of the hydration degree of cement, with a value of 1.0 when maintained for $90 \mathrm{~d}$ and 0.85 when maintained for $28 \mathrm{~d}$; and $\gamma_{C}$ refers to the correction coefficient of cement variety, with a value of 1.0 for Portland cement and 1.0 minus the content of admixtures for other cements.

Empirical model based on the compressive strength of concrete: A calculation model was proposed by Di Xiaotan of Chinese Academy of Architectural Sciences[21]. In the model, concrete strength is the main parameter, and the environment, maintenance conditions, and cement variety are the influencing factors. $x_{c}=\alpha_{1} \alpha_{2} \alpha_{3}\left(\frac{60}{f_{c u}}-1.0\right) \sqrt{t}$

where $f_{c u}$ refers to the compressive strength of concrete and $\alpha_{1}, \alpha_{2}, \alpha_{3}$ refer to the parameters of maintenance conditions, cement variety, and environment, respectively. The specific values were provided by Reference [21].

Based on these calculation theories and models and considering the main influential conditions in the experimental process, this study proposed a calculation formula of the carbonation depth of concrete with axial compressive strength maintained for $28 d$ and $\mathrm{CO}_{2}$ concentration and carbonization time of concrete as the main factors.

$x_{c}=\frac{\beta}{f_{c u}} \sqrt{C \cdot t}$

The conversion of the cube and axial compressive strengths of a prism uses $f_{c}=0.88 \alpha_{1} \alpha_{2} f_{c u}$. Incorporation into Formula (9) yields.

$x_{c}=\frac{0.88 \alpha_{1} \alpha_{2} \beta}{f_{c}} \sqrt{C \cdot t}$

where $\alpha_{1}$ refers to the correction coefficient of strength with a value of 0.76 for concrete $\mathrm{C} 50$ and below, 0.82 for highstrength concrete $\mathrm{C} 80$, and linear interpolation in the middle; $\alpha_{2}$ refers to the brittle reduction factor with a value of 1.0 for concrete $\mathrm{C} 40$ and below, 0.87 for high-strength concrete $\mathrm{C} 80$, and linear interpolation in the middle; $\beta$ refers to the coefficient related to fiber type determined by experimental data; and $f_{c}$ refers to the axial compressive strength of concrete $\left(\mathrm{N} / \mathrm{mm}^{2}\right)$.

\subsubsection{Model Verification Based on Experimental Data}

According to the principle of mathematical statistics, the experimental data and formula were fitted with carbonation depth as the function and carbonization time as the independent variable to draw the carbonation depth curves of different types of fiber-reinforced concrete and test the reliability of the formula. The experimental data of the $0.5 \%$ mixing ratio was regarded as an example. The calculation models of different fibers were as follows:

$0.5 \% \mathrm{C}, x_{c}=\frac{73.51 \alpha_{1} \alpha_{2}}{f_{c}} \sqrt{C \cdot t}-1.79127$

The fitting degree was 0.98188 , and the mean square error was 0.11289 .

$0.5 \% \mathrm{~A}, x_{c}=\frac{88.55 \alpha_{1} \alpha_{2}}{f_{c}} \sqrt{C \cdot t}-1.17845$

The fitting degree was 0.96923 , and the mean square error was 0.31948 .

$0.5 \% \mathrm{C} / \mathrm{A}, x_{c}=\frac{53.25 \alpha_{1} \alpha_{2}}{f_{c}} \sqrt{C \cdot t}+0.12692$

The fitting degree was 0.9697 , and the mean square error was 0.15475 . The accuracy of the model was good. 


\section{Conclusions}

To resolve the high brittleness and poor toughness of concrete, a novel method of adding carbon and aramid fibers into concrete was developed. Through experiments on concrete samples mixed with different types and ratios of fibers, the study analyzed the mechanical properties and durability of the samples. The following conclusions could be drawn:

(1) The compressive strength of concrete samples mixed with carbon and hybrid fibers initially increased and then decreased with the increase in the fiber mixing ratio. The strength of concrete mixed with aramid fiber is inversely proportional to the mixing ratio of fiber and is higher than that of ordinary concrete. Many vertical cracks are observed on the surface of the fiber-reinforced concrete samples, indicating good toughness.

(2) The elastic modulus and compressive strength of the fiber-reinforced concrete show the same change trend. The addition of fiber slightly influences the elastic modulus of concrete. Therefore, during calculation, the elastic modulus of ordinary concrete can be used directly.

(3) The carbonation resistance of different types of fiberreinforced concrete is enhanced compared with that of ordinary concrete. The effect on the carbon fiber-reinforced concrete is the most significant, followed by that on the hybrid fiber-reinforced concrete and aramid fiber-reinforced concrete. The mixing ratio of fiber is inversely proportional to anti-carbonation capacity. Carbonation depth calculation formulas based on compressive strength, $\mathrm{CO}_{2}$ concentration, and carbonization time are proposed through an experiment and verified by the test data. The calculation value shows a good agreement with the test value.

This study combined tests and theoretical analysis to obtain the improvement degrees of concrete reinforced by different types of fibers and mixing rates. A carbonation depth calculation formula of fiber-reinforced concrete was proposed based on the test data. The formula provides a reference to actual engineering. The parameter selection of the model exerts a certain influence on applicable conditions due to the multiple factors that affected the present carbonation experiment. In future studies, environmental humidity and other factors should be introduced to broaden the application scope of the model.

\section{Acknowledgements}

The study was supported by the Science and Technology Project of Hebei Provincial Transportation Department (Grant No. Y-2012046).

Access article distributed under the terms of the Creative Commons Attribution Licence

\section{References}

1. Hu Haitao, Li Ni, Xiong Jie, "Research on Quasi-static mechanical properties of short cut aramid fiber-reinforced cement mortar". Journal of Zhejiang university of technology, 28(04), 2011, pp.505509.

2. Wang, Wenjie, Chouw, Nawawi, "The behaviour of coconut fibre reinforced concrete (CFRC) under impact loading". Construction and Building Materials, 134, 2017, pp.452-461.

3. Graça, R.J.R, Rodrigues, J.A, Loja, M.A.R. Jorge, P.M., "Multiscale stress analysis in CFRC using microscope image data of carbon fibres". Composite Structures, 176, 2017, pp.471-480.

4. López-Gálvez, Hector, Rodriguez-Millán, Marcos, Feito, Norberto, Miguelez, Henar, "A method for inter-yarn friction coefficient calculation for plain wave of aramid fibers". Mechanics Research Communications, 74, 2016, pp.52-56.

5. Zhao, Huifang, Zhang, Meiyun, Zhang, Sufeng, Lu, Jinbei, "Influence of Fiber Characteristics and Manufacturing Process on the Structure and Properties of Aramid Paper". Polymer-Plastics Technology and Engineering, 51(2), 2012, pp.134-139.

6. Yang, Hui, Song, Hengwen, Zhang, Shi, "Experimental investigation of the behavior of aramid fiber reinforced polymer confined concrete subjected to high strain-rate compression". Construction and Building Materials, 95, 2015, pp.143-151.

7. Hong, Sungnam, Park, Sun-Kyu, "Behavior of Concrete Beams with Peel-Plied Aramid-Fiber-Reinforced Polymer Plates". Mechanics of Composite Materials, 52(1), 2016, pp.43-54.

8. Dong Jiangfeng, Wang Qingyuan, Qiu Cichang, Zhu Yanmei, Yan Huiqun, "Experimental study on fracture properties of concrete beams strengthened with externally bonded CFRP sheets". China Civil Engineering Journal, 43(S2), 2010, pp.76-82.

9. Cheng Donghui,YI Yamin,Wang Tianfeng, "Plastic Performance Test and Finite Element Analysis on the Concrete Continuous Beams Strengthened with CFRP Sheets". China Railway Science, 32(03), 2011, pp.27-32.

10. Shang Shouing, Li Zhibing, Peng Hui, "Experimental Research and Finite Element Analysis of the Interfacial Bonding Behavior of CFRP-Concrete Interface". Journal of Hunan University (Natural Sciences), 41(06), 2014, pp. 43-51.
11. Wen Jie, Xia Zhenhai, Choy Fred, "Damage detection of carbon fiber reinforced polymer composites via electrical resistance measurement". Composites Part B: Engineering, 42(1), 2011, pp. 77-86.

12. Deng Zongcai, Li Jianhui, "Experimental and theoretical research on flexrual performance of RC beams strengthened with hybrid fiber sheets". Engineering Mechanics, 26(02), 2009, pp.115-123.

13. Song, Weimin, Yin, Jian, "Hybrid effect evaluation of steel fiber and carbon fiber on the performance of the fiber reinforced concrete". Materials, 9( 8), 2016, pp.704.

14. He Junyong, Yao Lining, Shi Bin, Wu Yongming, "Study on the damping structure and intelligent dynamic energy dissipation of flexible fiber concrete". China Concrete and Cement Products, (02), 2006, pp.40-42.

15. Zhang, Shui, Li, Guozhong, Chen, Juan, Ning, Chao, Li, Baojia, "Performance of chemical modified Kevlar fiber reinforced cement-based composites". Acta Materiae Compositae Sinica, 28(03), 2011, pp.109-114.

16. Qiao Yanjing, Yang Zhiqian, Liu Jianzhong, Xu Degen, Li Lin, Zhou Huaxin, "Application of high performance aramid fiber in cement based composite materials". Concrete, (01), 2015, pp. 9497.

17. Niu Ditao, Chen Li-ting, Zhang Chengzhong, "Calculating model for gas diffusivity in concrete". Journal of $x i$ 'an architectural science and technology university(Natural Science), (06), 2007, pp.741-745.

18. PAPADAKIS V G., "Effect of supplementary cementing materials on concrete resistance against carbonation and chloride ingress". Cement and Concrete Research, 30(2), 2000, pp.291-299.

19. Cao Mingli, Ding Yanbing, Zheng Jinxuan, Wang Lixing, Du Shaocong, "Overview the mechansim and forecast model of concrete carbonization". Concrete, (09), 2012, pp.35-38+46.

20. Zhang $\mathrm{Yu}$, Jiang Lixue, "A practical mathematical model of concrete carbonation depth based on the mechanism". Industrial Construction, (01), 1998, pp.16-19+47.

21. Di Xiaotan, Zhou Yan, "Durability design of concrete structure". Journal of Fuzhou University(Natural Science), (S1), 1996, pp.8994 